\title{
Analysis on Energy-Saving and Green Technology and Optimization Measures in Civil Engineering Construction
}

\author{
Delin Qi*
}

Shenzhen Guangyilian Construction Engineering Co., Ltd. E-mail: qidl@163.com

\begin{abstract}
Energy-saving and green technology plays an important role in the development of civil engineering in the new era. The concept of energy saving and environmental protection can not only ensure the coordination between civil engineering construction and urban living environment, but also reduce construction cost and avoid energy consumption. This article analyzes the common problems in the construction of civil engineering, and discusses the application of energysaving and green technology in civil engineering. Corresponding measures are also put forward to promote the energysaving and green technology, as well as the sustainable development of the construction industry.
\end{abstract}

Keywords: Civil Engineering; Construction; Green and Environmental Protection

With the development of social economy, the scale of urban construction is expanding, and the technical level of civil engineering construction in China is becoming more and more perfect. However, the shortcomings of traditional civil engineering technology are gradually revealed. With the increase of people's awareness of environmental protection in China, new requirements for engineering construction technology need to be put forward in the industry on the basis of social and economic benefits, and the concept of energy saving and green and environmental protection need to be applied to the field of civil engineering construction. On the one hand, it can meet China's sustainable development policy; on the other hand, it can avoid environmental pollution during engineering construction, ensure the daily life quality of urban residents and create a green and stable living environment.

\section{Common problems in civil engi- neering construction}

\subsection{Weak awareness of energy saving and}

\section{green environmental protection}

Most enterprises are influenced by the traditional construction concept, and do not have the awareness of energy saving and green environmental protection in the process of civil engineering construction. Due to the lack of correct construction guiding concept, irregular behaviors often occur during construction. The construction quality of the project is neglected in order to seek its own interests, which leads to serious resource consumption in civil engineering and serious pollution problems to the surrounding environment, further exacerbating the contradiction between engineering and environment and society, greatly reducing the construction quality and efficiency of civil engineering, causing greater economic losses for enterprises and affecting economic and social benefits.

\subsection{Lack of scientific management}

Civil engineering is a huge energy-consuming project, and the realization of scientific and reasonable energy-saving and environmental protection measures is 
the basis for improving the engineering construction quality and avoiding environmental pollution in the construction process. The lack of scientific and reasonable management measures in civil engineering construction will lead to a large number of resource consumption. According to the current situation of civil engineering construction management in China, enterprises often lack consideration of the relationship between various factors and energy-saving and environmental protection construction, lack understanding of the key points of energy-saving and environmental protection technology, and lack effective supervision system and measures, resulting in inadequate implementation of the treatment scheme for waste of civil engineering resources, unresolved related problems, and inability to eliminate the quality and environmental risks existing in civil engineering.

\subsection{Lack of advanced equipment}

In the process of civil engineering construction, construction enterprises often adopt traditional civil engineering construction technology and use relatively old equipment to save costs. Although the construction cost is seemingly reduced, it is easy to cause a large amount of consumption of raw materials because the equipment is relatively old. The equipment can not meet the environmental protection standards, so it is easy to cause pollution problems, such as noise and exhaust gas problems. Due to the serious lack of advanced equipment in civil engineering construction, it brings difficulty in keeping up with the progress of the project and purpose of energy saving and environmental protection cannot be achieved.

\section{The energy-saving and green technology in civil engineering con- struction}

\subsection{Optimizing the structural design of buildings}

When designing civil engineering, engineers need to consider the geographical location, combination, orientation, spacing and other issues of construction engineering, and also need to consider hydrology, geology, surrounding environment, etc., and carry out specific and scientific design by investigating the environmental conditions of the site and referring to relevant data. In general, the external structure of construction projects is often with the problem of poor thermal insulation performance. The design of walls, doors and windows can ensure that the indoor temperature is always kept at an appropriate level. In the actual design process, considering the comprehensive lighting conditions, it is necessary to handle the relationship between the areas of doors, windows and walls and heating energy consumption, and control the areas of doors, windows and walls. If necessary, thermal insulation curtains and window boards can be used to achieve the effect of energy conservation and environmental protection. From the point of view of building structure, the roof of building engineering has better thermal insulation performance than doors and windows, mainly because the roof is in direct contact with hot-pressed airflow. Generally speaking, the difference of roofing materials and building structures will affect the heat loss of roofing. Therefore, the rational application of green energy-saving and environmental protection technologies can ensure that the heat of roofing will not cause huge losses. In the actual design process, the appropriate energy-saving technology should be chosen according to the roof structure. For example, if the roof structure is slope-shaped, this characteristic needs to be considered when choosing thermal insulation materials.

\subsection{Application of the concept of green and environmental protection in the process of engineering construction}

In the process of construction, the reasonable application of the concept of green and environmental protection can guarantee the construction quality of the project and avoid the pollution problem. Heating technology is an important part of engineering construction. Most civil engineering projects generally adopt residential floor heating technology or centralized hot water heating technology, but these two technologies can easily consume more resources, especially water resources. Therefore, the concept of green and environmental protection is applied to the heating technology of civil engineering, such as circulating water pump heating technology. The circulating water pool is developed in the construction site, through which the wastewater, precipitation and drainage ditch sewage are treated respectively, thus effectively treating the sewage while realizing the recycling of precipitation water and reversing rainfall.

\subsection{Rational utilization of renewable re- sources}


Civil engineering will consume a lot of resources and energy in the construction process, resulting in high energy consumption and high pollution. The fossil fuels and electric energy consumed in the construction are non-renewable and the process of resource consumption is irreversible. Applying the concept of energy saving and environmental protection to the construction process of civil engineering can further improve the utilization rate of renewable resources. In the construction process, other renewable resources instead of non-renewable resources, such as solar energy, are applied by enterprises in the construction process of civil engineering, which can reduce the consumption of fossil fuels and avoid additional pollution in the project. Construction enterprises should combine the characteristics of the development of the times, broaden the utilization channels of renewable resources, reduce the use of fossil fuels and electric energy, and adopt new energy sources such as solar energy, geothermal energy and wind energy in civil engineering construction as much as possible to further realize the coordination between engineering construction and the natural environment for human survival. However, renewable resources can't be used blindly. According to the characteristics of civil engineering and renewable energy, renewable energy should be applied reasonably to avoid unnecessary waste.

\subsection{Strengthening the construction of en- ergy-saving management}

At present, there are many kinds of construction materials used in the construction of civil engineering in China, and the types of energy used in civil engineering are also different. In order to realize the rational management of resources, it is necessary to plan resources and construction materials reasonably from different aspects. For resources with dangerous nature, protective measures can be taken and their use can be planned accordingly; when selecting construction equipment, it is required to follow the principle of energy saving and environmental protection and avoid unnecessary energy consumption as much as possible; due to the scarcity of water resources in China and a large amount of water resources will be consumed in the use of civil engineering, so water resources should be recycled in the construction process to minimize unnecessary waste of resources; energy-saving and environmental protection technologies should be scientifically and rationally introduced to achieve rational use of resources.

\section{Measures to optimize energy-sav- ing and green technology in civil engineering construction}

\subsection{Strictly control pollution in construction}

The most common pollution problems in civil engineering construction are dust, waste, and noise. In order to realize energy saving and environmental protection in civil engineering construction, enterprises should adopt enclosure on the construction site according to the actual construction amount of civil engineering in the early stage of construction, and cover the dusty places as much as possible. It is necessary to regularly use sprinkler and air purification devices to control the dust and waste on the construction site, and improve the air quality of the surrounding environment. In the process of construction, equipment and machinery with low operating sound should be used or they should be divided into different construction stages to avoid the influence of noise on surrounding residents as much as possible. To control the water pollution in the construction process, it is necessary for relevant enterprises to build corresponding sewage treatment devices on the construction site to treat the water pollution in the construction process, so as to avoid serious pollution of surrounding rivers and underground water quality caused by direct discharge. It is also needed to reasonably treat and use natural sewage, and recycle water resources as much as possible.

\subsection{Strengthen the concept of energy saving and environmental protection of enterprises}

With the continuous expansion of urban construction scale, the number of urban buildings also increases, accompanied by a series of ecological environment deterioration problems. In order to achieve the strategic goal of sustainable development in China, the national government has issued corresponding policies to control land resources reasonably. Civil engineering is a project that causes the greatest damage to land resources. In order to respond to the call of the national government for civilized and green construction, civil engineering related enterprises need to change the traditional concept of civil engineering construction in time, and carry out regular learning activities on the concept of sustainable and green 
development. The overall design of civil engineering should incorporate the concept of ecological environment protection and green sustainability. Relevant enterprises should regularly carry out green construction training to ensure that managers and grass-roots construction personnel improve their awareness of energy saving and environmental protection, implement green and environmental protection construction in a true sense, and improve the economic benefits of enterprises on the basis of ensuring ecological balance and avoiding over-exploitation and damaging the environment as much as possible.

\subsection{Optimize the construction scheme of civil engineering}

Civil engineering construction is easily affected by various factors. In order to achieve the national sustainable development strategic goal, it is necessary for related enterprises to incorporate the concept of energy saving and green environmental protection when formulating construction schemes in the early stage of construction. In the process of construction practice of civil engineering, due to the uncertainty, the difficulty of green and environmental protection technology is greatly increased. Therefore, in architectural design, it is necessary to consider the potential influencing factors in the construction process in advance, adjust the application of energy-saving and green construction technology, and standardize the construction behavior, so as to work out a scientific, reasonable and green civil engineering construction scheme. Based on various considerations, the construction scheme of civil engineering should not only ensure the construction quality and safety, but also achieve the goal of green construction according to the actual construction needs and the concept of energy saving and environmental protection. Civil engineering construction schemes are generally adjusted according to the technical characteristics of energy conservation and environmental protection, the surrounding environment of the construction site and the strength of enterprises, and the production materials, such as manpower, construction materials and construction costs, should be reasonably distributed, so as to ensure the quality of civil engineering construction, improve construction efficiency, minimize energy consumption and reduce energy pollution as much as possible, thus achieving the goal of green construction of enterprises and the national sustainable development goal.

\section{Conclusion}

To sum up, the application of energy-saving and green technology in civil engineering is not only a necessary condition for the development of modern society, but also an important guarantee for maintaining ecological balance and ensuring the basic living environment of human beings. In the early stage of China's economic development, too much attention was paid to economic development, resulting in serious energy waste. With the improvement of people's awareness of environmental protection, the strategic goal of sustainable development promulgated by the national government requires relevant enterprises to make corresponding changes. In civil engineering construction, the concept of energy saving and environmental protection is introduced; the traditional construction concept is changed; energy-saving buildings are built; the coordination between the construction site and the living environment of urban residents is well coordinated; the benefits of energy saving and environmental protection are improved; and the construction quality of civil engineering is improved to ensure the economic benefits of enterprises.

\section{References}

1. Zhang Z. Analysis of energy-saving construction technology in housing construction (in Chinese). Home 2020; (21): 72-73.

2. Li B. On the application of energy-saving technology in industrial and civil construction (in Chinese). Science and Technology Innovation 2020; (20): 142-143.

3. Liu X, Zhang Y, Xu W. Application of energy-saving and environmental protection technology in building construction (in Chinese). Building Technique Development 2020; 47(13): 155-157. 